\title{
Influence of laser photocoagulation on choroidal capillary cytoarchitecture
}

\author{
Robyn H Guymer, Gregory S Hageman, Alan C Bird
}

\begin{abstract}
Aim-To identify if laser photocoagulation induces morphological changes specifically related to the choroidal capillary endothelial processes that protrude into Bruch's membrane.

Methods-Two human eyes and one adult macaque monkey eye received retinal laser photocoagulation that was just suprathreshold, before enucleation or exenteration. They were examined by electron microscopy to determine the length of the endothelial processes emanating from the choroidal capillaries in the region around the laser burn. One human and two monkey untreated eyes were used for comparison.
\end{abstract}

Results-In human eyes, there was no increase in the number of processes 15 hours after laser treatment but at 5 days the processes were more numerous and longer within $400-500 \mu \mathrm{m}$ of the burn than in the untreated half of the same eye. The processes were longer 9 days after photocoagulation in the monkey, when compared with untreated monkeys, and some breached the elastic lamina, a phenomenon not seen in the untreated eyes. Qualitative differences were also noted in the endothelial cell processes following photocoagulation. Neovascularisation was not observed.

Conclusions-Protrusion of choroidal endothelial cell processes into Bruch's membrane is a normal anatomical feature but the number, length, and morphology of the processes change following mild photocoagulation. It is plausible that these processes may play a part in the clearance of debris from Bruch's membrane, and represent an early stage of angiogenesis. If the latter is true prophylactic laser photocoagulation at just suprathreshold levels may carry a risk of inducing choroidal neovascularisation.

(Br f Ophthalmol 2001;85:40-46)

There is considerable interest in the possible long term beneficial effects of laser photocoagulation in patients with high risk drusen as part of age related maculopathy (ARM). The rationale for treatment comes from observations that, following laser treatment, drusen distant from the site of photocoagulation resorb. ${ }^{1}$ Several pilot studies using a variety of protocols have repeated the observation, and some authors claim a short term visual benefit. ${ }^{2-9}$ As a result, randomised clinical trials have been initiated in patients with high risk
ARM. The mechanism whereby photocoagulation induces resolution of the drusen is unknown, but it must account for the observation that disappearance of drusen occurs over many months, ${ }^{9}$ and that the process begins in close proximity to the burn and then spreads outwards over an ever increasing area of the fundus (Fig 1).

It has been suggested by others that processes of choroidal pericytes penetrate into Bruch's membrane and may contribute to the clearance of drusen as a result of observations in primates following experimental photocoagulation. ${ }^{10}$ Moreover, it was implied that they may have a physiological role in clearing debris from Bruch's membrane. It is well established that choroidal capillaries also have cellular processes that penetrate the outer portion of Bruch's membrane. They have been described in normal eyes of many species, but they have received little attention until recently. ${ }^{11-18}$ Their physiological significance is uncertain. Similar structural specialisations of the endothelial cell have been identified in other tissues, and various functions have been attributed to them, such as stabilising the thin fenestrated vascular wall of the renal vasa recti, ${ }^{19}$ sensing extracellular matrix in kidney through chemoreceptors and mechanoreceptors, and phagocytosis in trabecular meshwork and lung. ${ }^{21} 21$

A variety of potential functions has been proposed for these endothelial processes in the choroid. It has been suggested that they may be important to metabolic exchange between choroid and retinal pigment epithelium, or contribute to debris in Bruch's membrane. ${ }^{16}$ It is also possible that they may influence the clearance of debris from Bruch's membrane in humans. The number and size of the processes do not correlate with age, nor any index of age change in the RPE, such as autofluorescence of the RPE or residual body content of the RPE, although there is a weak linear association with Bruch's membrane thickness. ${ }^{18}$ It has also been suggested that choroidal endothelial processes may represent an early phase of choroidal neovascularisation, and they have been described as a low turnover vascular remodelling process, which occurs in response to preceding vascular degeneration in the choroid. ${ }^{22}{ }^{23}$ It is well recognised that focal erosion of basement membrane around endothelial cells, with subsequent protrusion of cell processes through these defects is a sign of nascent angiogenesis in oncology studies. ${ }^{24}{ }^{25}$ It is therefore possible that the same processes are potential precursors of neovascularisation if the appropriate extracellular conditions prevail. 

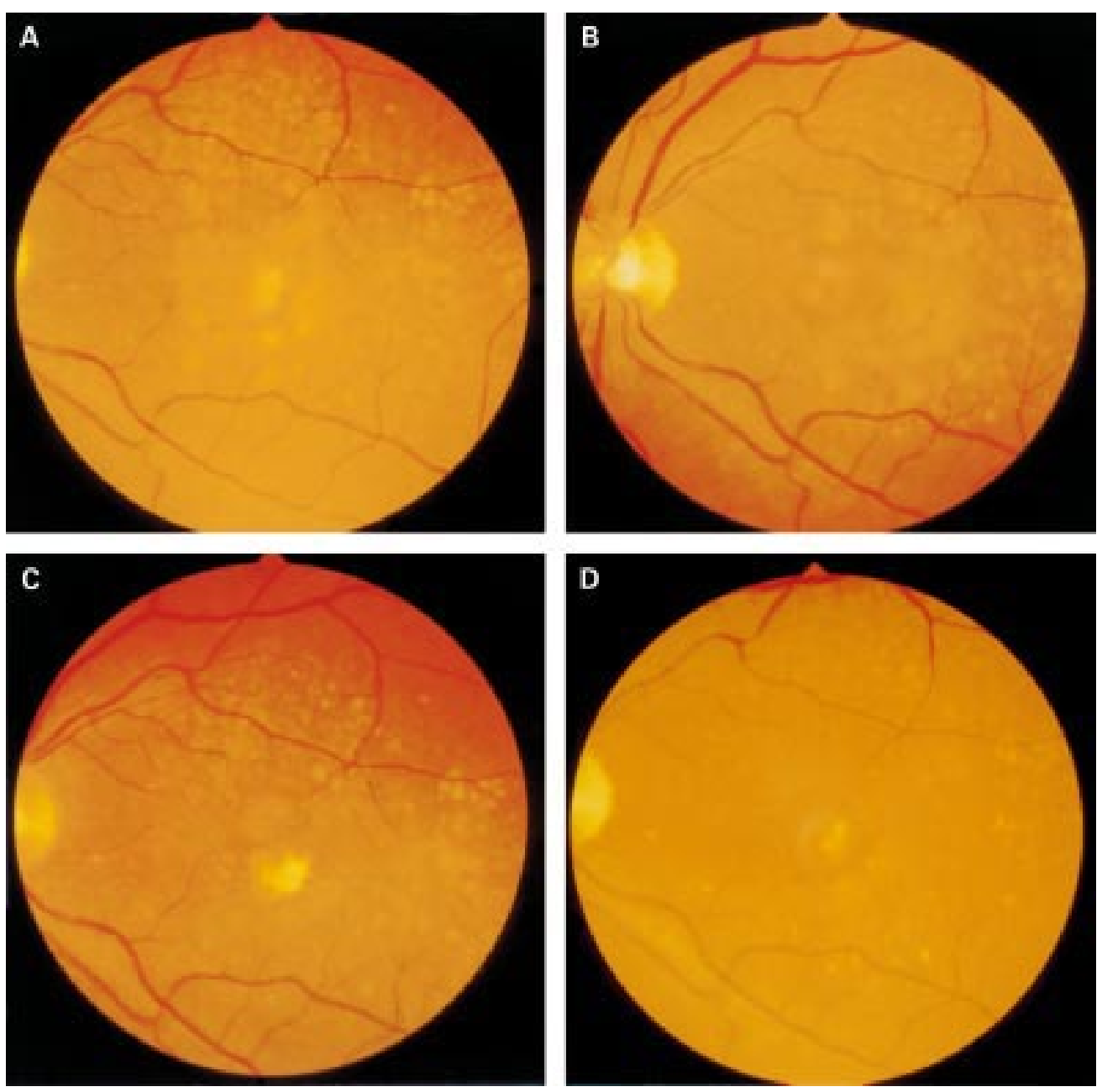

Figure 1 Fundus photographs of a patient who received prophylactic photocoagulation treatment for high risk drusen. (A) Before treatment with 12 spots $\times 200 \mu m \times 0.2$ seconds at a power to just whiten the retina. The lesions are placed in a ring $1000 \mu \mathrm{m}$ from the fovea; (B) 3 months after photocoagulation; (C) 6 months after photocoagulation; (D) 20 months after photocoagulation. Note that the clearance starts around the area of the laser burns and spreads out circumferentially and that the effect is continuing at 20 months.

Given that resolution of drusen and choroidal neovascularisation ${ }^{26-30}$ may occur following photocoagulation, and that the presence of choroidal capillary endothelial cell processes may contribute to the therapeutic effect of laser photocoagulation, we sought evidence that laser photocoagulation influences their density and/or morphology.

\section{Materials and methods}

Three female patients (patient 1, 58 years old; patient 2, 45 years old; patient 3, 61 years old) undergoing exenteration as part of their treatment for meibomian gland carcinoma, consented to donate their normal globes to research. The research was approved by the ethics committee of Moorfields Eye Hospital. Before surgery, the eye of patients 2 and 3 had just suprathreshold photocoagulation applied with an argon laser to the inferior macular using variables similar to those used in current prophylactic studies of ARM. ${ }^{9}$ Patient 2 had seven $200 \mu \mathrm{m}$ diameter burns, of $200 \mathrm{~ms}$ duration and $140 \mathrm{~mW}$, applied 15 hours before surgery, and patient 3 had twenty $200 \mu \mathrm{m}$ burns, of $200 \mathrm{~ms}$ duration and $200 \mathrm{~mW}$, applied 5 days before surgery. All three eyes were fixed within 15 minutes of exenteration in mixed aldehydes $(2.5 \%$ paraformaldehyde and 2\% glutaraldehyde) in $100 \mathrm{ml}$ sodium cacodylate buffer $\mathrm{pH} 7.4$ and prepared for electron microscopy. The eyes that had been photocoagulated had segments taken from the superior macula, at least $4 \mathrm{~mm}$ from any laser burn, to compare with specimens taken from the inferior macula that incorporated the laser lesions.

Eyes from three adult macaque monkeys were enucleated after perfusion fixation in paraformaldehyde and then emersion fixed as described above. One of the monkeys had 12 suprathreshold photocoagulation burns (200$400 \mathrm{~ms}$ duration and $200-400 \mathrm{~mW}$ ) applied to the right eye only with a Keeler indirect diode laser, 9 days before sacrifice. The untreated eyes served for comparison.

All globes were hemisected by a circumferential incision through the pars plana and the posterior pole was isolated. Sections of the maculas were obtained from the central macula in eyes that were not treated and from areas equidistant from the horizontal raphe in the superior and inferior macula in eyes with laser burns. Those specimens taken from the treated half always included a visible laser lesion. 
Table 1 Number of endothelial cellular processes in untreated and photocoagulated human and monkey eyes

\begin{tabular}{|c|c|c|c|c|c|}
\hline \multirow[b]{2}{*}{ Subject } & \multicolumn{3}{|l|}{ Untreated } & \multicolumn{2}{|l|}{ Treated } \\
\hline & $\begin{array}{l}\text { Number per } \\
100 \mu \mathrm{m}\end{array}$ & $\begin{array}{l}\text { Range per } \\
100 \mu m\end{array}$ & $\begin{array}{l}\text { Maximum length } \\
\text { of process }(\mu m)\end{array}$ & $\begin{array}{l}\text { Number per } \\
100 \mu \mathrm{m}\end{array}$ & $\begin{array}{l}\text { Maximum length } \\
\text { of process }(\mu \mathrm{m})\end{array}$ \\
\hline P1 & 5.7 & $(3-8.3)$ & 1.0 & - & \\
\hline $\mathrm{P} 2$ & 6.5 & $(3.3-9.1)$ & 0.8 & $2.9-8.8$ & 0.5 \\
\hline P3 & 4.5 & $(0.7-8.3)$ & 0.7 & $1.8-13.5$ & 2.6 \\
\hline M1 & 10.4 & $(9-12)$ & 0.8 & - & \\
\hline M2 & 3.8 & $(2-5)$ & 0.7 & - & \\
\hline M3 & 8.4 & $(2-13)$ & 0.9 & $3.1-11.4$ & 1.5 \\
\hline
\end{tabular}

Tissues were dehydrated in acetone and propylene oxide, post-fixed in osmic acid, and embedded in Araldite for electron microscopy. Ultrathin sections were stained with uranyl acetate and lead citrate. Sections were examined with an electron microscope (Jeol), and the number of processes on the internal aspect choroidal endothelial cell per $100 \mu \mathrm{m}$ length of Bruch's membrane were counted, measured, and photographed. A process was only counted if it clearly transgressed the basal lamina of the choriocapillaris. Untreated eyes had 10 con-
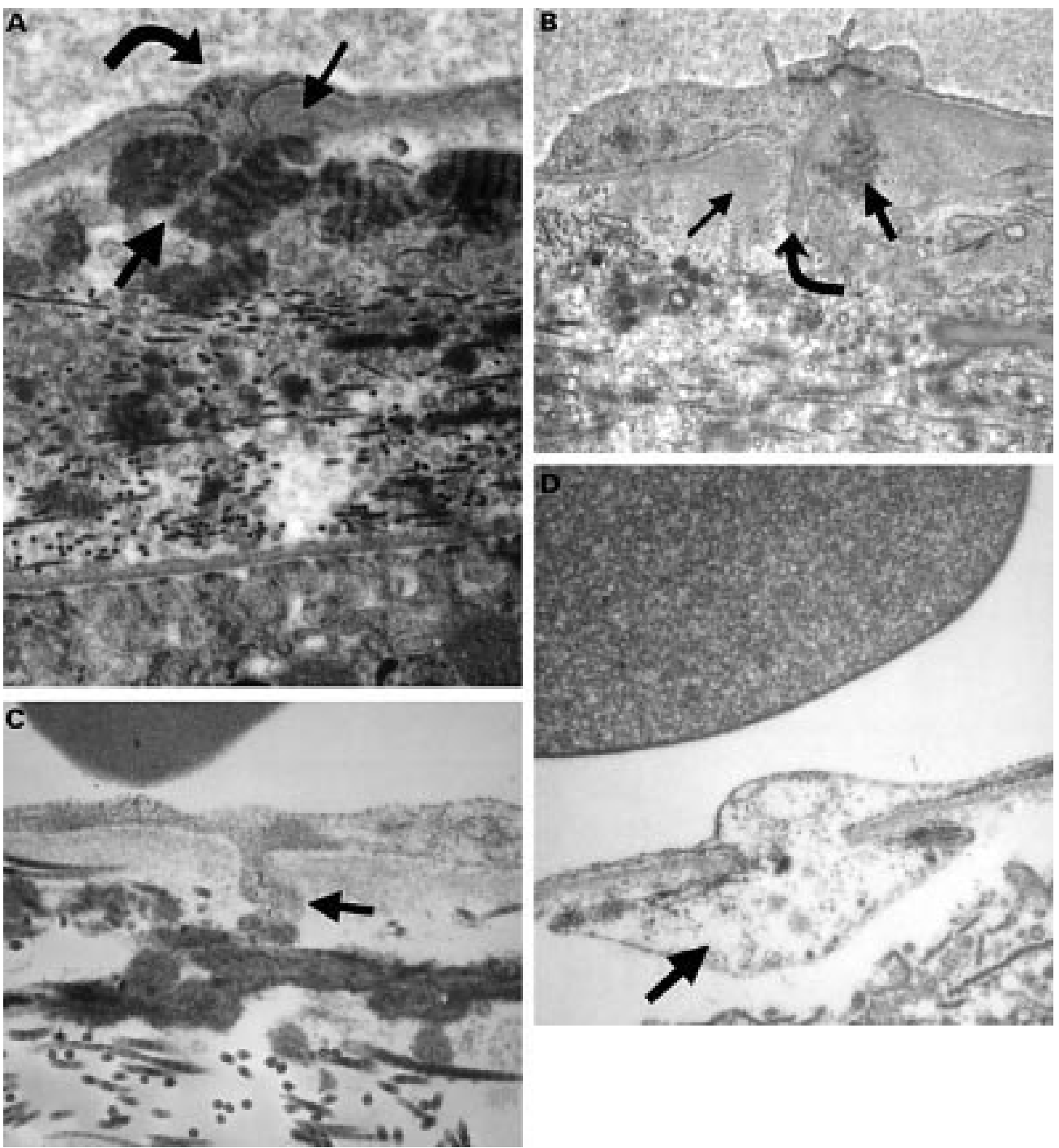

Figure 2 Electron micrograph of choriocapillaris and Bruch's membrane in human eyes. (A) An untreated area of patient 3 (final magnification 48 000), and (B) an 71 year old man (final magnification 50 000). These show focal thickening of basal lamina (small arrow) around the base of a cell process (curved arrow) associated with long spacing collagen (LSC) (thick arrow) in the outer collagenous zone (OCZ). (C) 22 year old man (final magnification 100 000), (D) an 82 year old woman (final magnification 80 000); these show a magnified appearance of the processes (thick arrow). 

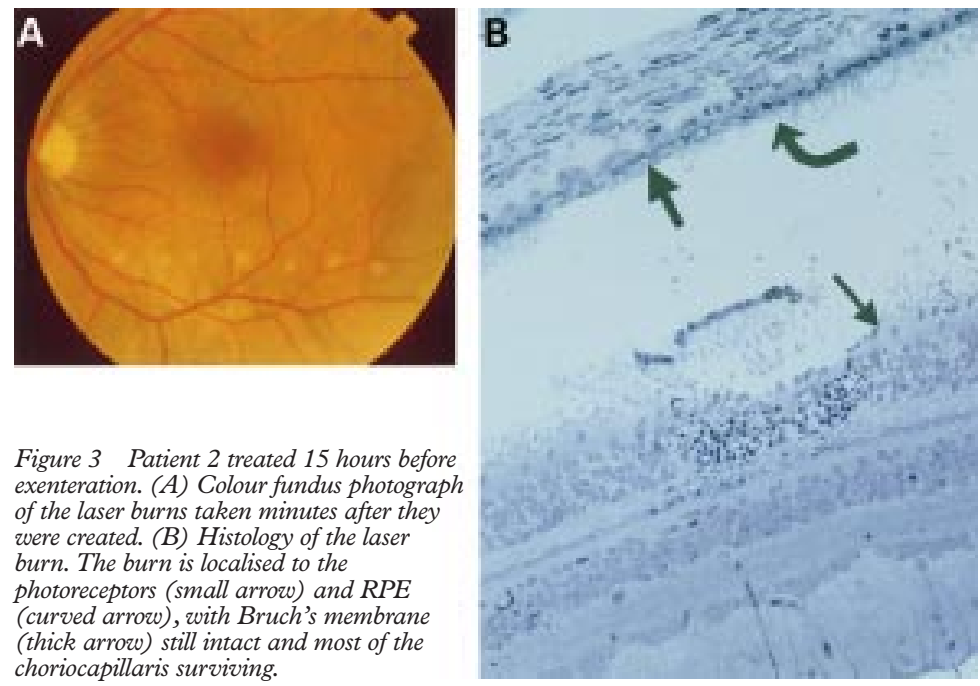

Figure 3 Patient 2 treated 15 hours before exenteration. (A) Colour fundus photograph of the laser burns taken minutes after they were created. (B) Histology of the laser burn. The burn is localised to the photoreceptors (small arrow) and RPE (curved arrow), with Bruch's membrane (thick arrow) still intact and most of the choriocapillaris surviving.

\section{Results (Table 1)}

UNTREATED REGIONS OF HUMAN EYES

In patient 1 (P1), who did not receive photocoagulation, the average number of endothelial cell processes per $100 \mu \mathrm{m}$ was 5.7 with a range of 3.0-8.3. The longest individual process was $1.0 \mu \mathrm{m}$

In the superior half of the macula of patient 2 (P2) in which no photocoagulation had been undertaken there was an average of 6.5 processes per $100 \mu \mathrm{m}$ (3.3-9.1). The longest individual process was $0.8 \mu \mathrm{m}$.

In the superior control half of the macula of patient 3 (P3) there was an average of 4.5 processes per $100 \mu \mathrm{m}(0.7-8.3)$. The longest individual process was $0.7 \mu \mathrm{m}$.

No processes were observed to breach the elastic layer of Bruch's membrane. The processes were often associated with focal thickening of the endothelial cell basement membranes. Each eye had large quantities of long spacing material in the outer collagenous layer of Bruch's membrane, often in close juxtaposition to the endothelial processes and focal thickening in the basal lamina (Fig 2).

PHOTOCOAGULATED REGIONS OF HUMAN EYES The laser lesion destroyed only focal areas of photoreceptors and RPE, leaving Bruch's membrane intact and the choriocapillaris patent except in a few instances where it was absent at the site of the burn (Figs 3 and 4).

In patient 2 , who had photocoagulation 15 hours before exenteration, the average number of processes per $100 \mu \mathrm{m}$ ranged between 2.9-8.8 (Fig 5). The longest process was 0.5 $\mu \mathrm{m}$ at $200-300 \mu \mathrm{m}$ from the laser burn but did not breach the elastic lamina of Bruch's membrane. The number of processes was maximal at 100-400 $\mu \mathrm{m}$ from the laser burn (Fig 5). There was no statistically significant difference between the maximum number of processes seen after laser treatment and that seen in the control half of the same eye $(\mathrm{p}=0.38$, two tailed test).

In patient 3, who had laser photocoagulation 5 days before exenteration, the average number of processes in each $100 \mu \mathrm{m}$ from the laser burn ranged between $1.8-13.5 \mu \mathrm{m}$ with the maximum number being between 400-500 $\mu \mathrm{m}$ from the burn and minimum number directly under the burn (Fig 6). The number of processes at $400-500 \mu \mathrm{m}$ from the burn was statistically different from the average of 4.5 that was seen in the untreated half of the same eye $(p=0.009$, two tailed test). The longest process was $2.6 \mu \mathrm{m}$ at $0-100 \mu \mathrm{m}$ from the laser burn. Processes of this size were not seen in the untreated specimens, but none breached the elastic lamina of Bruch's membrane. Neovascularisation was not seen.

As found in the untreated eyes, the processes were often associated with focal thickening of the endothelial cell basement membranes and large quantities of long spacing material in the outer collagenous layer of Bruch's membrane, often in close juxtaposition to the endothelial processes and focal thickening in the basal lamina.

\section{UNTREATED MONKEY EYES}

Monkey 1 had no treatment and the total number of processes per $100 \mu \mathrm{m}$ was 10.4 with a range of 9-12. The longest process was $0.8 \mu \mathrm{m}$

Monkey 2 had no treatment and the total number of processes per $100 \mu \mathrm{m}$ was 3.8 with a range of $2-5$. The longest process was $0.7 \mu \mathrm{m}$.
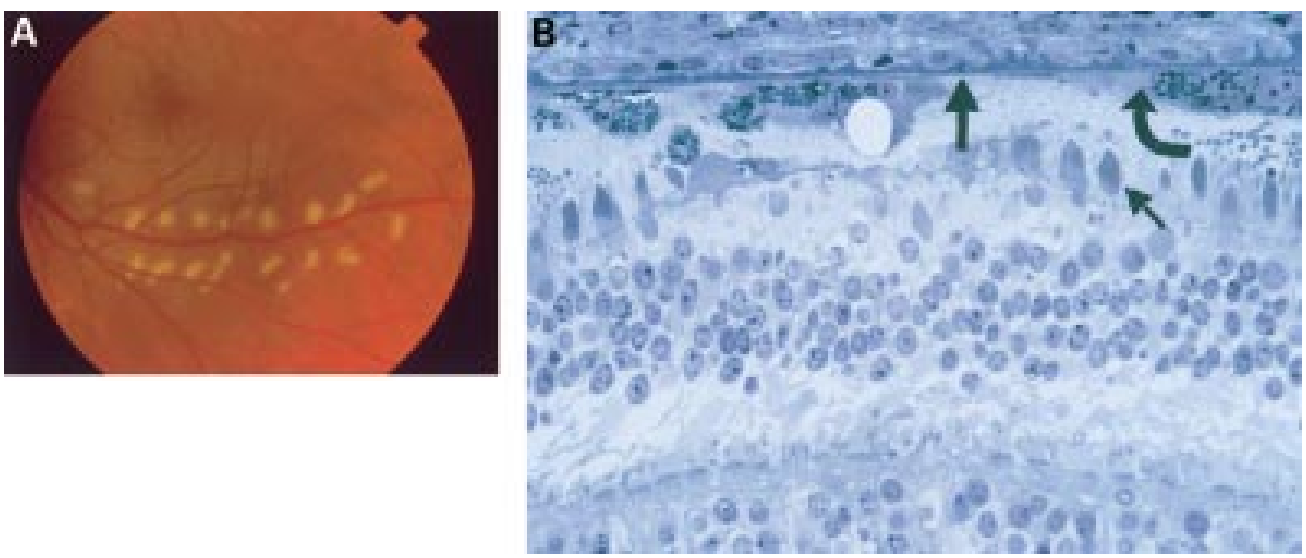

Figure 4 Patient 3 lasered 5 days before exenteration. (A) Colour fundus photograph of the laser burns taken minutes after they were created. (B) Histology of the laser burn. The burn is localised to the photoreceptors (small arrow) and RPE (curved arrow), with Bruch's membrane (thick arrow) still intact and most of the choriocapillaris surviving. 


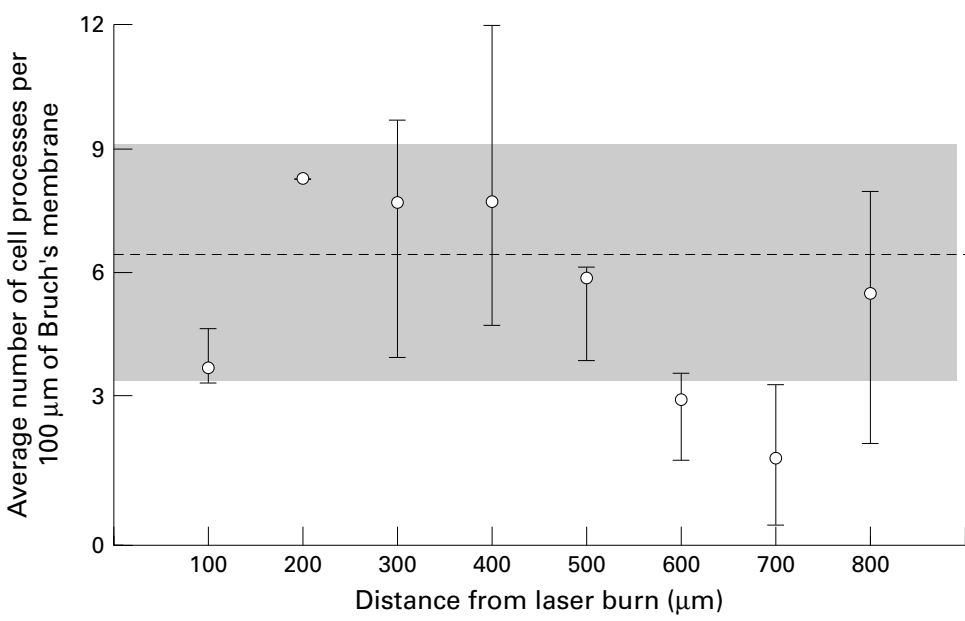

Figure 5 Graph of the average number of processes per $100 \mu \mathrm{m}$ of Bruch's membrane against the distance from the laser burn in patient 2. Patient 2 received laser treatment 15 hours before exenteration. The shaded area represents the range in the number of processes seen in the untreated half of patient 2's retina. The broken line is the average number seen per $100 \mu \mathrm{m}$.

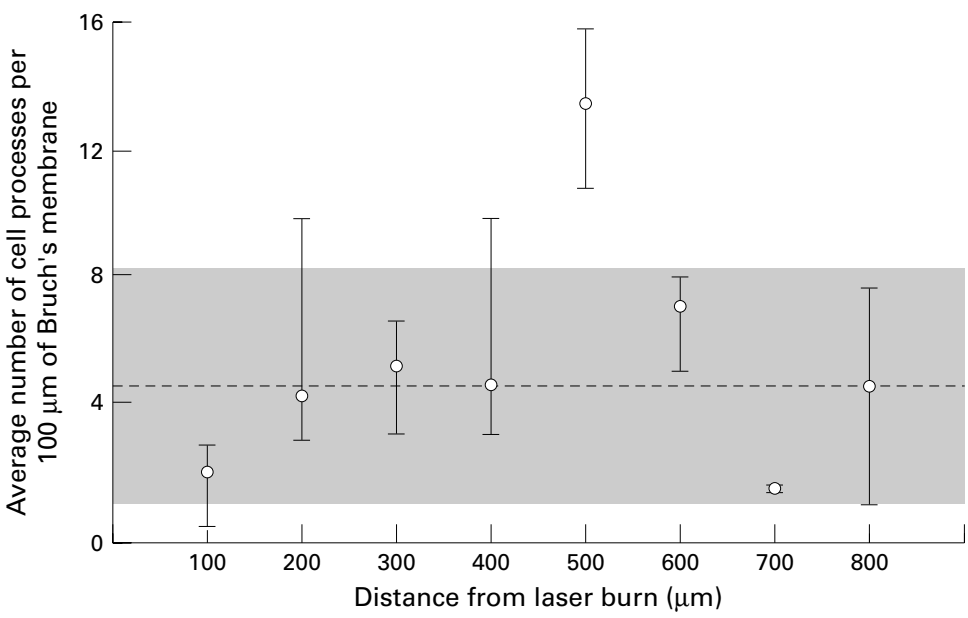

Figure 6 Graph of the average number of processes per 100 mm of Bruch's membrane against the distance from the laser burn in patient 3. There were 5 days between photocoagulation and exenteration. The shaded area represents the range in the number of processes seen in the untreated half of patient 3's retina. The broken line is the average number seen per $100 \mu \mathrm{m}$. Note the increase in number of processes 400-500 $\mu \mathrm{m}$ from the laser burn.

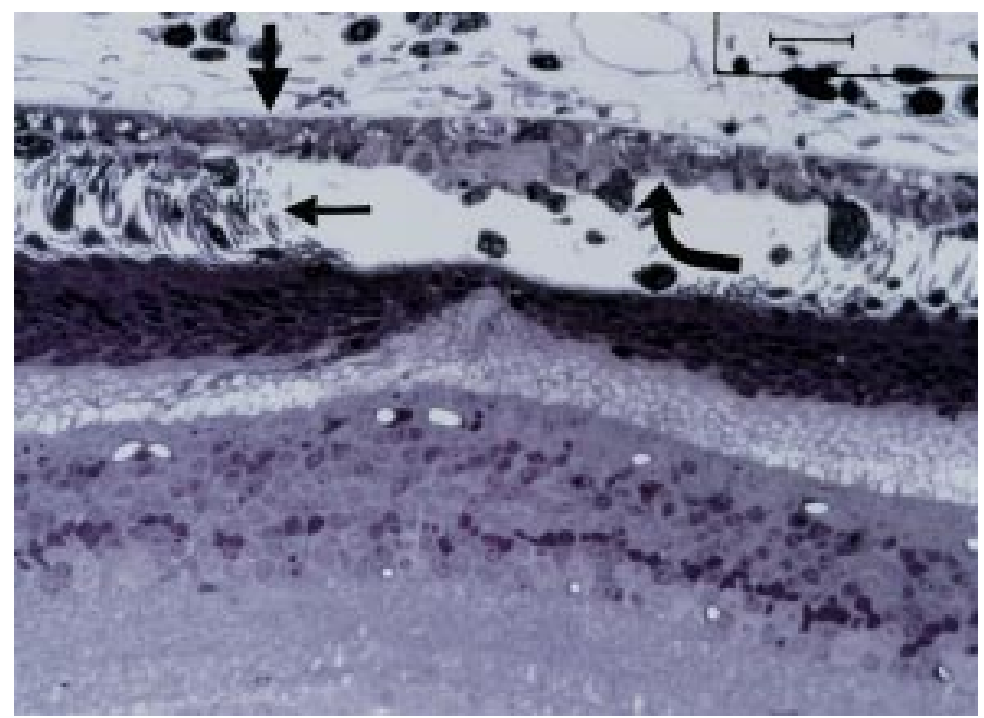

Figure 7 Monkey eye after photocoagulation. Histology of the laser burn. The burn is localised to the photoreceptors (small arrow) and RPE (curved arrow), with Bruch's membrane still intact (thick arrow) and most of the choriocapillaris surviving.
Monkey 3 had laser photocoagulation to the right eye, while the left eye had no treatment. The non-treated left eye had a total number of processes per $100 \mu \mathrm{m}$ of $8.4 .^{2-13}$ The longest process was $0.9 \mu \mathrm{m}$.

None of the control specimens had processes that breached the elastic lamina of Bruch's membrane. Focal thickenings in the endothelial basement membranes were noted where the processes protruded into Bruch's membrane, but there was no long spacing material in the outer collagenous layer as seen in the human eyes.

\section{PHOTOCOAGULATED MONKEY EYE}

Laser photocoagulation destroyed a focal area of photoreceptors and the RPE, leaving Bruch's membrane intact and the choriocapillaris patent (Fig 7). The average number of processes ranged from 3.1-11.4 per $100 \mu \mathrm{m}$ with a large variability in the numbers at each distance from the burn. The number of processes was greatest at a distance of 500-700 $\mu \mathrm{m}$ from the laser burn, although this was not significantly different from that seen in the control eye of this monkey $(p=0.28)$. The longest process was $1.5 \mu \mathrm{m}$ at $800-900 \mu \mathrm{m}$ from the burn. Processes this size were not seen in the control eye of this monkey and $4 \%$ of processes at 500-600 and 800-900 $\mu \mathrm{m}$ from the burn breached the elastic lamina of Bruch's membrane (Fig 8A, B). There was no evidence of neovascularisation.

Qualitative differences were also noted in the endothelial cell processes when compared with those in control sections. The cytoplasm of the endothelial cells contained more intracytoplasmic organelles than was seen in untreated specimens (Fig 8C, D). Many cellular processes were seen that did not breach the basal lamina, and therefore were not counted in our analysis. However, they appeared to be displacing the basal lamina from the plasma membrane of the endothelial cell and may represent an early phase of formation of cellular protrusion into Bruch's membrane (Fig 8C, D).

\section{Discussion}

We have presented evidence that the cytoplasmic processes from the choroidal capillary endothelial cells increased in number and size in the human eye that was photocoagulated 5 days before exenteration. In the monkey eye treated 9 days before sacrifice, we noted longer processes than seen in untreated specimens, that extended through the elastic lamina of Bruch's membrane. The limitation of counting only those processes passing through the basal lamina of the capillary may have underestimated the influence of laser treatment on the endothelium since complex structures emanating from the endothelium were seen internal to the basal lamina, a phenomenon not seen in the untreated eyes. Changes have been noted previously in the choriocapillaris following photocoagulation including prominent, expanded rough endoplasmic reticulum, and an increase in the number of lysosomes. ${ }^{31} \mathrm{We}$ found similar evidence of morphological changes in the endothelial cells of the monkey, 

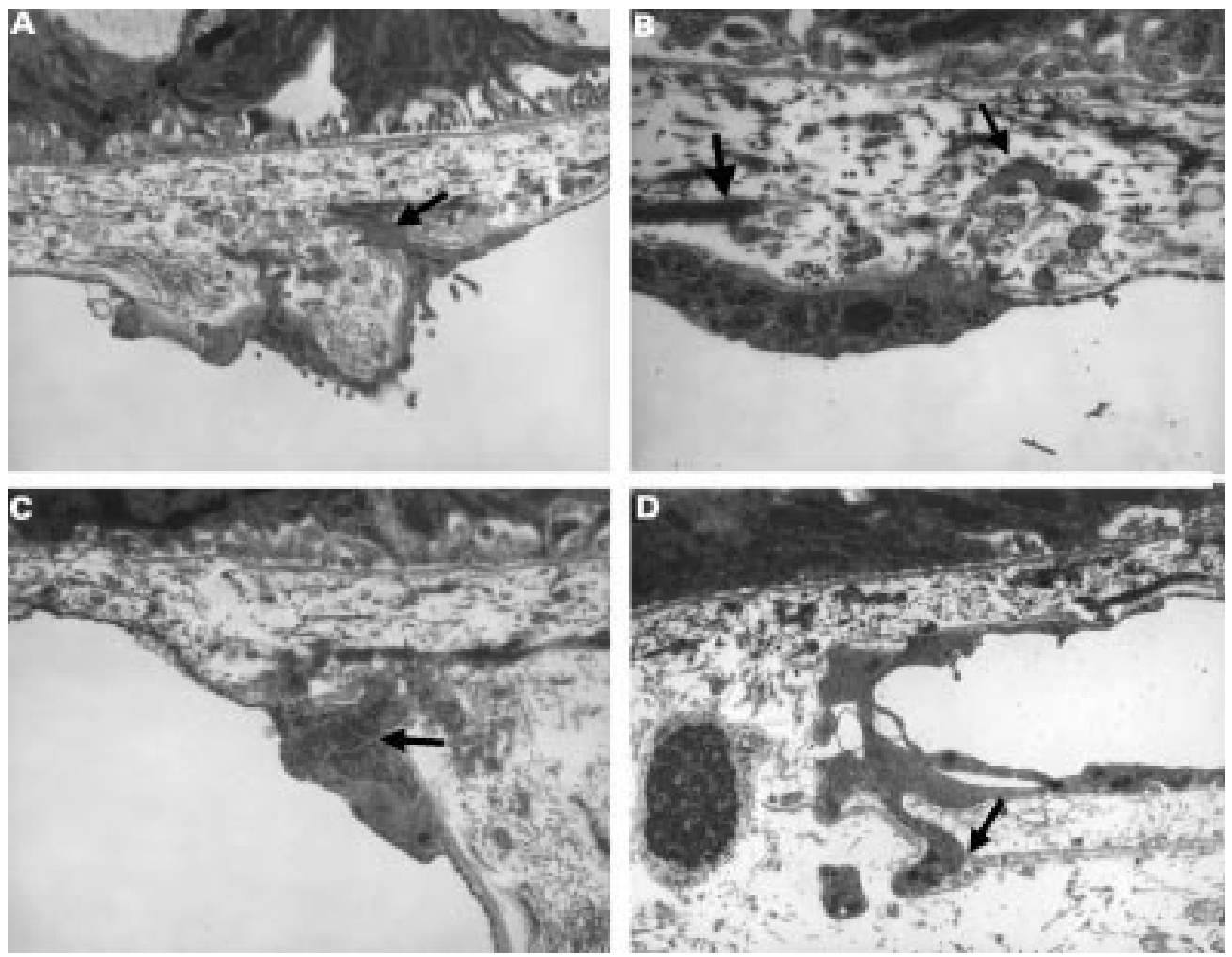

Figure 8 (A) Electron micrograph of a monkey's Bruch's membrane and choriocapillaris showing endothelial processes (small arrow) (final magnification 40 000) and (B) electron micrograph showing a process (small arrow) protruding through the elastic lamina of Bruch's membrane (thick arrow) (final magnification 80000 ). (C) Electron micrograph in which the endothelial cell appears to have an increase in cytoplasmic organelles (small arrow) (final magnification 48 000), and (D) electron micrograph with processes displacing the basal lamina (small arrow) of the endothelial cell (final magnification 32 000).

consistent with increased activity. We did not see any cellular processes from the RPE traversing the full width of Bruch's membrane as has occurred in rats following laser burns using high energy intensity. ${ }^{31}$

The potential relevance of these findings to the clearance of drusen following photocoagulation, and to neovascularisation, is unclear. It would be attractive if it were possible to demonstrate a long lived cellular response to photocoagulation to account for the time scale of resolution of drusen. We were unable to detect convincing evidence for phagocytosis of debris in Bruch's membrane by these processes as has been found in other tissues. ${ }^{20}{ }^{21}$ However, we cannot rule out the possibility that this exists as a normal function of endothelial cells of the choriocapillaris, and that this function is stimulated after photocoagulation. It is also possible that the endothelial cells may influence clearance of debris by modifying the biophysical properties of Bruch's membrane. This would have been more convincing in humans if the processes had transgressed the elastic lamina as was seen in the monkey eye, since it is at this level that the principal barrier to fluid flow exists. ${ }^{32}$ The interval between photocoagulation and histological examination is short and had it been longer more persuasive evidence may have been found.

Endothelial processes such as those examined in this study have been interpreted as nascent neovascularisation since the initial step in new vessel formation is the egress of endothelial cell processes through the basement mem- brane sheath accompanied by production of proteases. $^{22}{ }^{33} 34$ The observed increase of endothelial activity following laser treatment would be in accord with the finding that choroidal neovascularisation occurs consistently after heavy laser photocoagulation at the primate macula, ${ }^{28}$ and follows laser treatment in humans. ${ }^{29}$ However, we saw no new vessel formation, implying that the difference may be one of degree determined by the intensity of photocoagulation. Consequently, choroidal neovascularisation may be a distortion of what is a normal feature of the choroid. A fine line must exist between the upregulation of process formation after photocoagulation and nascent angiogenesis. It is possible only to speculate on the circumstances that allow inward growth of formed blood vessels from the choroid, and several factors have been considered as being potentially relevant. Imbalance of inhibitory and stimulating diffusible factors, changes in the physicochemical properties of Bruch's membrane, and the presence of macrophages may modulate this process. ${ }^{22}{ }^{35}$ It is also possible that the basal lamina of endothelial cells may influence the effects of the release of growth factors. It is of interest therefore that quite marked focal thickenings of the endothelial cell basal lamina was noted to surround the base of these processes, especially in the young. ${ }^{18}$ We have postulated that the role of this focal thickening of basal lamina may be to act to distribute mechanical forces around the cytoplasmic peg that anchors the cell to the extracellular matrix. If focal thickening also 
moderates the risk of neovascularisation, its absence in the elderly may serve to increase the risk of choroidal new vessel growth with age. It is hardly surprising that photocoagulation may alter the influences that regulate the generation of cellular processes intruding into Bruch's membrane which is normal, and choroidal neovascularisation as part of disease. The results of the clinical trials of prophylactic photocoagulation to patients with high risk drusen must be awaited before we can abandon concern over the potential induction of neovascularisation. $^{36}$ Our observations suggest that the use of low rather than high energy settings may reduce the risk, but may not obviate it totally.

We would like to thank Mr Robin Howes for help in EM preparation. We would like to thank Professor J Lund and Dr J Levitt who made the monkey work possible. Patients PC, JN, and SW who willingly donated their eye for research after exenteration are sincerely thanked as are $\operatorname{Dr} B$ Mulholland and the oculoplastic surgeons at Moorfields Eye Hospital for coordinating the collection of this rare material. Professors C Michel and $\mathrm{J}$ Squires, and Drs P Munro, C Neal, and M Chew provided valuable discussion and Miss C Bunce provided the data analysis.

1 Gass JD. Drusen and disciform macular detatchment and degeneration. Arch Ophthalmol 1973;90:206-17.

2 Cleasby GW, Nakanishi AS, Norris JL. Prophylactic photocoagulation of the fellow eye in exudative senile maculopathy. A preliminary report. Mod Probl Ophthalmol 1979;20 $141-7$.

3 Weizig PC. Treatment of drusen-related ageing macular degeneration by photocoagulation. Trans Am Ophthalmol Soc. $1988 \cdot 86 \cdot 276-90$.

4 Wetzig PC. Photocoagulation of drusen related macular degeneration: a long term outcome. Trans Am Ophthalmol Soc 1994;92:292-306.

5 Haut J, Renard Y, Kraiem S, et al. Preventive treatment using laser of age-related macular degeneration of the conusing laser of age-related macular degeneration of the contralateral eye after age-related macular deg
first eye. 7 Fr Ophtalmol 1991;14:473-6.

6 Sigelman J. Foveal drusen resorption one year after perifoveal laser photocoagulation. Ophthalmology 1991;98: 1379-83

7 Figueroa MS, Regueras A, Bertrand J. Laser photocoagulation to treat macular soft drusen in age related macular degeneration. Retina 1994;14:391-6.

8 Frennesson IC, Nilsson SEG. Effects of argon (green) laser treatment of soft drusen in early age-related maculopathy: a 6 months prospective study. $\mathrm{Br} \mathcal{F}$ Ophthalmol 1995;79: 905-9.

9 Guymer RH, Gross-Jendroska M, Owens SL, B et al. Laser treatment in subjects with high risk clinical features of (1) Ophthalmal 1998;115:595-603.

10 Duvall J. Tso M. Cellular mechanisms of resolution of drusen after laser coagulation. An experimental study. Arch Ophthalmol 1985;103:694-703.

11 Garron LK. The ultrastructure of the retinal pigment epithelium with observations on the choriocapillaris and Bruch's membrane. Trans Am Ophthalmol Soc 1963;61 545-88.

12 Leeson TS, Leeson CR. Choriocapillaris and lamina elastica (vitrea) of the rat eye. Br f Ophthalmol 1967;51:599-615.
13 Matsusaka T. Undescribed endothelial processes of the atsusaka $T$. Undescribed endothelial processes of the choriocapillaris extending to the retinal pigment epit
lium of the chick. Br $\mathcal{F}$ Ophthalmol 1968;52:887-92.

14 Yamamoto T, Yamashita H. Pseudopodia of choriocapillary endothelium. Fpn f Ophthalmol 1989;33:327-36.

15 Yamamoto T, Yamashita H. Psuedopodia of choriocapillary endothelium in ocular tissues. Fpn f Ophthalmol 1990;34: $181-7$.

16 Yamamoto $T$, Fukuda S, Obata $H$, et al. Electron microscopic observation of pseudopodia from choriocapillary endothelium. Fpn f Ophthalmol 1994;38:129-38.

17 Korte GE, Chase J. Additional evidence for remodelling of normal choriocapillaris. Exp Eye Res 1989;49:299-303.

18 Guymer RH, Bird AC, Hageman G. Choroidal capillary cytoarchitecture. What is the significance of endothelial processes into Bruch's membrane? Invest Ophthalmol Vis Sci (in press)

19 Taugner R, Kirchheim H, Forssmann WG. Myoendothelial contacts in glomerular arterioles and in the renal interlobuar arteries of rats, mouse and Tupaia belangeri. Cell Tissue Res 1984;235:319-25.

20 Grierson I, Day J, Unger WG, et al. Phagocytosis of latex microspheres by bovine meshwork cells in culture. Graefes Arch Clin Exp Ophthalmol 1986;224:536-44.

21 Gabbianni G. Majno G. Pathophysiology of small vessel permeability. In: Kaley G, Altura BM, eds. Microcirculation. Vol III. Baltimore: University Park Press, 1980:143-63.

22 Killingsworth MC. Angiogenesis in the early choroidal neovascularization secondary to age related macular degener tion. Graefes Arch Clin Exp Ophtalmol 1995;233:313-23

23 Heriot WJ, Henkind P, Bellhorn RW, et al. Choroidal neovascularization can digest Bruch's membrane. A break is not essential. Ophthalmology 1984;91:1603-8.

24 Ausprunk DH, Folkman J. Migration and proliferation of endothelail cells in preformed and newly formed blood vessels during tumour angiogenesis. Microvasc Res. 1977; $14: 53$.

25 Folkman J. Angiogenesis: Initiation and control. Ann NY Acad Sci 1982;401:212-27.

26 Galinos SO, Asdourian GK, Woolf MB, et al. Choroidovitreal neovascularization after argon laser photocoagulation. Arch Ophthalmol 1975;93:524-30.

27 Fine SL, Patz A, Orth DH, et al. Subretinal neovascularization developing after prophylactic argon laser photocoagulation of atrophic macular scars. Am $\mathcal{F}$ Ophthalmol 1976;82: $352-7$.

28 Ryan SJ. The development of an experimental model of subretinal neovascularization in disciform macular degeneration. Trans Am Ophthalmol Soc 1979;77:707-45.

29 Francois J, De Laey JJ, Cambie E, et al. Neovascularization after laser photocoagulation of macular lesions. Am f Ophthalmol 1975;79:206-10.

30 Pollack A, Korte GE, Weitzner AL, et al. Ultrastructure of Bruch's membrane after krypton laser photocoagulation. 1 Breakdown in Bruch's membrane. Arch Ophthalmol 1986; 104:1372-6.

31 Pollack A, Heriot WJ, Henkind P. Cellular processes causing defects in Bruch's membrane following krypton laser photocoagulation. Ophthalmology 1986;93:1113-19.

32 Moore DJ, Hussain AA, Marshall J. Age-related variation in the hydraulic conductivity of Bruch's membrane. Invest Ophthalmol Vis Sci 1995;36:1290-7.

33 Kalebic T, Garbisa S, Glaser B, et al. Basement membrane collagen: degradation by migrating endothelial cells. Science 1983;221:281-3.

34 Rifkin DB, Gross JL, Moscatelli D, et al. In: Nossel HL, Vogel HJ, eds. Pathobiology of the endothelial cell. New York: Academic Press, 1982:191-7.

35 Glaser BM, Extracellular modulating factors and the control of intraocular neovascularization. Arch Ophthalmol 1988;106:603-7.

36 Owens SL, Guymer RH, Gross-Jendroska M, et al. Fluorescein angiographic changes following prophylactic macular photocoagulation for high risk age-related maculopathy. Am f Ophthalmol 1999;127:681-7. 